latter has a nephrotoxic action, this is weak (Killen and Lance, 1960), and it is unlikely that such a small dose injected into the biliary tree would cause anuria. Neither did the blood pressure fall during operation to suggest tubular necrosis secondary to renal ischaemia. Renal failure often occurs as a consequence of a summation of insults to the kidney, and it has been suggested that, if possible, surgery should be postponed until several days after such radiological investigations (Milne, 1965). This case supports such a suggestion. The fact that this patient had only one kidney may have rendered him especially vulnerable to nephrotoxic agents.

An alternative possibility to a direct nephrotoxic action of iodipamide is that renal tubular damage occurred as a result of a fall in blood pressure. Iodipamide has a markedly hypotensive action (Saltzman and Sundström, 1960). At no time, however, did either patient's blood pressure fall below 110/70. Tubular necrosis from this cause is therefore unlikely.

It has been shown that the intravenous injection of both urographic and cholegraphic media provokes intravascular aggregation of red blood cells and a sludging effect (Lindgren and Saltzman, 1962). Whether this is responsible for the renal damage is not known.

The two cases quoted here suggest that iodipamide may on rare occasions cause renal failure where there are potentiating circumstances such as impaired hepatic function and pre- existing renal disease, or where surgical operations have been performed within hours of cholangiography.

\section{Summary}

Two cases of renal failure after intravenous cholangiography are described. In each case there was evidence that the patient was predisposed to develop renal failure. The first patient, who had unsuspected chronic pyelonephritis and a mild degree of jaundice, became anuric immediately after cholangiography. The second, who had only one kidney, developed oliguric renal failure after cholangiography, performed within 24 hours of laparotomy.

We are grateful to Professor H. Ellis for his encouragement and constructive advice in the preparation of this paper.

\section{REFERENCES}

Fink, H. E., jun., Roenigk, W. J., and Wilson, G. P. (1964). Amer. 7. med. Sci., 247, 201.

Harrow, B. R., and Winslow, O. P. (1966). Radiology, 87, 721.

Killen, D. A., and Lance, E. M. (1960). Surgery, 47, 260.

Lindgren, P., Nordenstam, H., and Saltzman, G. F. (1966). Acta radiol Diagn., 4, 129.

- and Saltzman, G. F. (1962), Acta radiol. (Stockh.), 57, 341.

Milne, M. D. (1965). Ann. Rev. Pharmacol., 5, 119.

Saltzman, G. F., and Sundström, K. A. L. (1960). Acta radiol. (Stockh.), $54,353$.

Seaman, W. B., Cosgriff, S., and Wells, J. (1963). Amer. F. Roentgenol., $90,859$.

\title{
Plasma Salicylate Levels in Acute Poisoning in Adults
}

\author{
STANLEY S. BROWN,* PH.D. ; JEAN C. CAMERON,* A.I.M.L.T. ; HENRY MATTHEW, $\dagger$ F.R.C.P.ED.
}

Brit. med. f., 1967, 2, 738-739

Admission of poisoned patients to hospital is steadily increasing (H.M.S.O. Report, 1966 ; Matthew and Lawson, 1966). Acute salicylate poisoning accounts for about $15 \%$ of these admissions in adults, and this particular type of poisoning is likely to present as a medical emergency wherever aspirin is freely available. Infants and toddlers are particularly sensitive to accidental or therapeutic poisoning with the drug, and there may be severe acid-base imbalance with no clear relation between the ensuing symptoms and the level of salicylate circulating in plasma. In adults, however, the situation is somewhat simpler. The normal therapeutic use of aspirin results in plasma salicylate levels of a few milligrams per $100 \mathrm{ml}$, while the treatment of rheumatic conditions may require the maintenance of levels of 25 or 30 mg. $/ 100 \mathrm{ml}$. Within this range and beyond, one or more of the features of salicylism become evident in those suffering from acute poisoning. In such cases a reliable clinical assessment of the severity of poisoning is often difficult to make (Cumming, Dukes, and Widdowson, 1964 ; Beveridge, Forshall, Munro, Owen, and Weston, 1964). The patient is almost invariably conscious and will usually admit to taking an overdose, but the quantity consumed will be exaggerated or minimized. In addition, vomiting will frequently have occurred, so that the actual amount of drug absorbed is unknown.

Our experience confirms that in these circumstances a knowledge of the plasma salicylate level, and its rate of change during the period immediately following admission, provides a valuable indication of the severity of poisoning and a very useful guide to the type of treatment required. In view of this, and

\footnotetext{
- University Department if Clinical Chemistry, Royal Infirmary, Edinburgh 3.

† Poisoning Treatment Centre, Royal Infirmary, Edinburgh 3.
}

of the fact that $60 \%$ of admissions to the Poisoning Treatment Centre occur between the hours of 5 p.m. and 8 a.m. the next day, it is clearly desirable to have available a method of estimating plasma salicylate which is simple and reliable enough to be carried out equally well by physicians in the ward side-room as by the staff of the chemical toxicology laboratory. We find that the method devised by Trinder (1954) meets these demands.

\section{Report}

During the two years from January 11964 to December 31 1966, 1,674 adults were admitted to the Poisoning Treatment Centre, Royal Infirmary, Edinburgh ; 214 of them were suspected on clinical grounds, or from the recent history, to be suffering from salicylate poisoning. In most of these cases estimations of plasma salicylate were performed, either in the ward side-room or in the laboratory, on heparinized blood specimens taken before gastric aspiration and lavage (Matthew, Mackintosh, Tompsett, and Cameron, 1966). The assay was that of Trinder (1954), as described in detail by MacDonald (1965). The reaction was most conveniently carried out with $5-\mathrm{ml}$. portions of reagent and $0.5 \mathrm{ml}$. of plasma or salicylate solution $(40 \mathrm{mg} . / 100 \mathrm{ml}$ ), in disposable tubes (10-ml. plain bottles, Stayne Laboratories Ltd.), the absorbance being measured in standard cuvettes (EEL Spectra); the whole procedure can be completed within 10 to 15 minutes.

The results are shown in the Table. Figures in parentheses represent estimations carried out in the laboratory for patients admitted to other hospitals in the region, although not necessarily for salicylate poisoning. One of this group of cases, however 
(with a level on admission of $43 \mathrm{mg} . / 100 \mathrm{ml}$.), is of interest as being an example of frank intoxication due to the percutaneous absorption of salicylate (von Weiss and Lever, 1964).

Numbers of Patients with Plasma Salicylate Levels in the Stated Ranges

\begin{tabular}{|c|c|c|c|c|c|c|c|c|}
\hline & & & & & & & \multicolumn{2}{|c|}{ on Admission } \\
\hline $\begin{array}{c}\text { Salicylate } \\
\text { (mg./100 ml.) }\end{array}$ & & $<6$ & $6-25$ & $26-35$ & $36-55$ & 56-75 & $76-95$ & $>95$ \\
\hline $\begin{array}{l}\text { Jan.-Dec. } 1965 \\
\Rightarrow \quad \text { " } 1966 \\
\end{array}$ & $\therefore$ & $\begin{array}{l}12(10) \\
29(10) \\
\end{array}$ & $\begin{array}{l}24(8) \\
46(13) \\
\end{array}$ & $17(3)$ & $\begin{array}{c}16 \\
25(3)\end{array}$ & $\begin{array}{r}7 \\
14\end{array}$ & $\overline{4}$ & $\overline{(1)}$ \\
\hline Total & & $41(20)$ & $70(21)$ & $31(3)$ & $41(3)$ & 21 & 4 & (1) \\
\hline
\end{tabular}

Most of the patients were admitted to the Poisoning Treatment Centre within 12 hours of ingesting what they believed to be an overdose of a salicylate preparation; in very few of these cases were other drugs, apart from codeine or phenacetin, taken concomitantly. In spite of the fact that, normally, aspirin is rapidly absorbed, with the more severely poisoned patients the plasma salicylate levels may rise steadily for as long as six hours after ingestion, if forced diuresis has not been initiated by this time. It is important to note the possibility of this effect, and that there may well be an increase in level of 5 to 10 $\mathrm{mg} . / 100 \mathrm{ml}$. in the period immediately following gastric washout. The subsequent rate of change depends on the treatment adopted, but the plasma salicylate level is then only one of several biochemical factors, particularly acid-base and electrolyte status, which must be taken into account in assessing the progress of each case.

Forced alkaline diuresis (Cumming et al., 1964) was the standard method of treatment in cases where the salicylate level exceeded $60 \mathrm{mg} . / 100 \mathrm{ml}$.

\section{Comment}

The most commonly used means of analysis of salicylate in biological fluids are the colorimetric methods of Brodie, Udenfriend, and Coburn (1944; cf. Routh and Dryer, 1961), of Smith and Talbot (1950), and of Trinder (1954) as described by MacDonald (1965). The first of these is perhaps the most sensitive and specific; the second is subject to interference from other phenolic drugs, notably phenacetin and phenolphthalein (Bowler, 1966) ; Trinder's method is the least sensitive of these and suffers from the disadvantage that the absorption spectrum of the ferric-salicylate complex shows a poorly defined maximum, and is subject to changes in temperature, $p \mathrm{H}$, and ionic strength, as well as to the presence of ions, particularly phosphate, which preferentially chelate with the reagent. Whilst such factors limit the value of the method in determining urinary salicylate, there is no difficulty in obtaining consistent results with plasma, with adequate reproducibility and accuracy in the range of most clinical significance-namely, 25 to 75 $\mathrm{mg} . / 100 \mathrm{ml}$. For this reason, and because it is simple and speedy enough to be carried out in the ward side-room,
Trinder's method is, in our opinion, the one of choice. It is, moreover, likely that satisfactory results could be obtained with a simple visual comparator without the need for a photoelectric colorimeter.

It should be emphasized that more refined means of analysis than colorimetric methods are needed to detect and estimate circulating acetylsalicylate (Morgan and Truitt, 1965) and the salicyl conjugates (Schachter and Manis, 1958).

The distribution of the results shown in the Table demonstrates the incidence and severity of salicylate poisoning among adults in an urban population of approximately 500,000. The average annual incidence corresponds to one admission for salicylate poisoning to the centre per 2,500 adults. Two-thirds of these cases were instances of mild poisoning, with plasma levels of less than $35 \mathrm{mg} . / 100 \mathrm{ml}$. on admission, and not rising significantly above this figure. With the remaining cases it is noteworthy how rarely plasma salicylate levels on admission exceeded $75 \mathrm{mg} . / 100 \mathrm{ml}$. This is primarily because the amount of drug actually absorbed is limited by the vomiting which is almost inevitably induced by overdosage of salicylate, as a result both of a local irritant effect and of central stimulation. Moreover, pylorospasm undoubtedly restricts the rate of absorption of salicylate, so that prompt admission to hospital and effective gastric wash-out are particularly valuable in lessening the severity of the poisoning.

\section{Conclusion}

The estimation of plasma salicylate by the method of Trinder (1954) is simple and reliable enough to be undertaken by physicians in the ward side-room, and affords a valuable guide to the severity of salicylate poisoning in adults.

\section{REFERENCES}

Beveridge, G. W., Forshall, W., Munro, J. F., Owen, J. A., and Weston, I. A. G. (1964). Lancet, 1, 1406.

Bowler, R. G. (1966). International Association of Forensic Toxicologists: Bulletin, vol. 3 , no. 4, p. 3 .

Brodie, B. B., Udenfriend, S., and Coburn, A. F. (1944). F. Pharmacol. exp. Ther., 80, 114.

Cumming, G., Dukes, D. C., and Widdowson, G. (1964). Brit. med. Y., 2, 1033.

General Register Office (1966). Report on Hospital In-patient Enquiry for 1962. H.M.S.O., London.

MacDonald, R. P. (1965). Stand. Meth. clin. Chem., 5, 237.

Matthew, H., and Lawson, A. A. H. (1966). Quart. F. Med., 35, 539.

Mackintosh, T. F., Tompsett, S. L., and Cameron, J. C. (1966). Brit. med. 7., 1, 1333.

Morgan, A. M., and Truitt, E. B. (iy65). 7. pharm. Sci., 54, 1640.

Routh, J. I., and Dryer, R. L. (1961). Stand. Meth. clin. Chem., 3, 194.

Schachter, D., and Manis, J. G. (1958). 7. clin. Invest., 37, 800.

Smith, M. J. H., and Talbot, J. M. (1950). Brtt. F. exp. Path., 31, 65.

Trinder, P. (1954). Biochem. f., 57, 301.

von Weiss, J. F., and Lever, W. F. (1964). Arch. Derm., 90, 614. 